\title{
TINGKAT KEPUASAN KONSUMEN TERHADAP KUALITAS PRODUK DAN PELAYANAN BALI BAKERY
}

\author{
Eka Kadalora, A.A.P.Agung Suryawan Wiranatha*, Amna Hartiati \\ PS Teknologi Industri Pertanian, Fakultas Teknologi Pertanian, Universitas Udayana, Kampus Bukit \\ Jimbaran, Badung, Kode pos : 80361; Telp/Fax : (0361) 701801.
}

Diterima 01 Maret 2019 / Disetujui 12 Agustus 2019

\begin{abstract}
ABSTRAK
Tujuan dari penelitian ini adalah untuk 1) Mengetahui atribut-atribut yang dianggap penting oleh konsumen dalam pencapaian kepuasan konsumen Bali Bakery 2) Mengetahui tingkat kepuasan konsumen pada produk dan jasa yang diberikan oleh Bali Bakery 3) Menentukan atribut-atribut yang perlu mendapat prioritas di Bali Bakery, berdasarkan tingkat kesesuaian antara kepentingan dan kinerja dalam memberikan kepuasan kepada konsumen. Data penelitian diperoleh dengan menyebarkan sebanyak 187 kuisioner ke konsumen Bali Bakery cabang Hayam Wuruk Denpasar. Metode Importance Performance Analysis digunakan untuk mengetahui tingkat kepuasan konsumen terhadap kualitas produk dan kualitas pelayanan. Hasil penelitian menunjukkan bahwa konsumen merasa puas dengan kualitas produk dan kualitas jasa yang diberikan perusahaan. Tingkat kepuasan konsumen terhadap kualitas produk sebesar $80,34 \%$ dan kualitas pelayanan adalah sebesar $81,27 \%$. Atribut-atribut yang perlu mendapat prioritas adalah seluruh variabel yang berada di kuadran A, yaitu harga produk terjangkau, kemasan produk (take away) yang mampu menjaga produk agar tidak rusak hingga ke tempat tujuan, tersedianya lapangan parkir yang memadai, karyawan Bali Bakery memberikan pelayanan yang sama tanpa memandang status sosial, dan Bali Bakery memiliki jam buka yang sesuai dengan keinginan konsumen.
\end{abstract}

\section{ABSTRACT}

The aim of this study are 1) To find out the attributes that are considered important by consumers in order to achieve the consumer satisfaction of Bali Bakery 2) To determine the level of consumer's satisfaction on the products and services provided by Bali Bakery 3) To determine the attributes that considered to get priority in Bali Bakery, based on the level of suitability between interests and performance to provide the satisfaction to the consumers. The data of this study was obtained by distributing 187 questionnaires to the consumers of Bali Bakery Hayam Wuruk Denpasar branch. The Importance Performance Analysis method was used to determine the level of consumer satisfaction related to product quality and service quality performed by the company. The results of the study indicate that consumers were satisfied toward the quality of the product and the quality of services provided by the company. The level of consumer satisfaction toward the product quality was $80,34 \%$ and toward the service quality was $81.27 \%$. The attributes that need to be prioritized were all of variables in quadrant $A$, namely affordable product prices, product packaging that was able to keep the product from being damaged to its destination, the availability of adequate parking space, employees of Bali Bakery providing the same service regardless of social status, and the Bali Bakery restaurant

*Korespondensi Penulis:

Email : agung_suryawan@unud.ac.id 
established the opening hours in accordance to the needs of consumers.

Keywords: Consumer Satisfaction, Importance Performance Analysis, Cartesian Diagram.

\section{PENDAHULUAN}

Produksi makanan oleh perusahaan pangan telah berkembang cukup pesat. Hal tersebut dikarenakan pangan merupakan kebutuhan primer masyarakat. Perkembangan yang pesat tersebut akan menciptakan persaingan antar perusahaan makanan, sehingga harus menunjukkan keunggulan yang dimiliki perusahaan masing-masing. Oleh sebab itu, kepuasan konsumen merupakan salah satu faktor yang krusial agar perusahaan dapat terus berkelanjutan, apabila perusahaan tidak memperhatikan hal ini, dikhawatirkan akan berdampak buruk bagi usaha itu sendiri, seperti menurunnya pendapatan dan penurunan jumlah konsumen.

Menurut Supranto (1997) jasa akan menjadi sesuatu yang bermanfaat apabila didasarkan pada kepentingan konsumen dan kinerjanya bagi perusahaan, artinya perusahaan harus mencurahkan perhatiannya pada hal-hal yang dianggap penting oleh konsumen. Hal tersebut dikarenakan keberadaan konsumen sangat penting sebagai pendapatan utama perusahaan. Perusahaan harus berusaha memaksimalkan pelayanaan dalam pemenuhan kebutuhan konsumen (Dwininarsih, 2009). Menurut Kotler (1989) cara terbaik suatu perusahaan untuk menguasai dan memenangkan persaingan adalah dengan mengambil sudut pandang konsumennya. Berdasarkan tingkat kepuasaan konsumen dalam studi kasus pada beberapa bidang usaha yang dilakukan oleh Iswari dkk. (2015) Jentrasaswin dkk. (2018) dan juga Ranitaswari dkk. (2018).

\section{Tujuan Penelitian}

Berdasarkan uraian pokok permasalahan yang telah dijelaskan, maka tujuan penelitian ini adalah 1) Mengetahui atribut-atribut yang dianggap penting oleh konsumen dalam pencapaian kepuasan konsumen Bali Bakery 2) Mengetahui tingkat kepuasan konsumen pada produk dan jasa yang diberikan oleh Bali Bakery 3) Menentukan atribut-atribut yang perlu mendapat prioritas di Bali Bakery, berdasarkan tingkat kesesuaian antara kepentingan dan kinerja dalam memberikan kepuasan kepada konsumen.

\section{METODE PENELITIAN}

Penelitian ini dimulai dengan studi literatur untuk mencari referensi teori yang relevan dengan kasus atau permasalahan yang ditemukan, setelah itu didapatkan topik penelitian yang berjudul analisis tingkat kepuasan konsumen terhadap kualitas produk dan kualitas pelayanan yang diberikan perusahaan, kemudian dilanjutkan dengan perumusan masalah dan tujuan penelitian, lalu dilakukan analisa menggunakan metode Importance Performance Analysis yaitu sebuah teknik analisis deskriptif yang diperkenalkan oleh John A. Martilla dan John C. James tahun 1977, metode ini digunakan untuk mengetahui pengaruh secara parsial antara kualitas produk dan tingkat kepuasan konsumen, dan jasa pelayanan dan tingkat kepuasan konsumen. Selain itu digunakan juga untuk mengetahui pengaruh secara simultan antara kualitas produk dan jasa pelayanan terhadap tingkat kepuasan konsumen. Penelitian dilanjutkan dengan penentuan responden sebanyak 30 konsumen di Conato Bakery cabang Teuku Umar, Denpasar untuk uji validitas dan reliabilitas kuisioner. Sedangkan sebanyak 187 konsumen di Bali Bakery cabang Hayam Wuruk yang bertempat di Jalan Hayam Wuruk nomor 183, Denpasar sebagai responden pada penelitian ini (Metode Slovin). 


\section{Pengolahan Data}

1. Uji validitas dalam penelitian ini untuk mengukur validitas kuisioner menggunakan teknik Product Moment. Uji reliabilitas dalam penelitian ini menggunakan metode Cronbach Alpha. Reliabilitas adalah indeks yang menunjukkan sejauh mana suatu alat ukur dapat dipercaya dan dapat diandalkan (Singarimbun dan Effendi, 1989). Alat ukur dikatakan reliabel jika menggunakan koefisien alpha lebih besar dari 0.468. Semakin besar nilai alpha cronbach, maka semakin tinggi tingkat reliabilitas kuisioner penelitian yang dilakukan

2. Analisis Indeks Kepuasan adalah hasil perhitungan dari rumus Indeks Kepuasan Konsumen. Importance Performance Analysis menggunakan diagram kartesius merupakan suatu bangun yang dibagi atas empat bagian yang dibatasi oleh dua buah garis yang berpotongan tegak lurus pada titik-titik (X), (Y), dimana $\mathrm{X}$ merupakan rata-rata dari skor tingkat kepuasan karyawan dan $\mathrm{Y}$ adalah rata-rata dari skor tingkat kepentingan seluruh variabel. Analisis tingkat kepentingan dan kepuasan perusahaan diperoleh dengan cara menghitung jumlah skor penilaian setiap variabel. Rata-rata penilaian kepentingan dan kepuasan konsumen dibagi menjadi empat bagian ke dalam diagram kartesius, yaitu kuadran A (Tingkatkan Kerja) kuadran B (Pertahankan Kerja) kuadran C (Prioritas Rendah) kuadran D (Cenderung Berlebihan)

\section{HASIL DAN PEMBAHASAN}

\section{Gambaran Umum Perusahaan}

Bali Bakery cabang Hayam Wuruk Denpasar berdiri sekitar awal tahun 1998 dan dalam perkembangan usahanya semakin mengalami peningkatan dari tahun ke tahun meskipun saat ini telah banyak berdiri perusahaan sejenis yang menjadi pesaing dari Bali Bakery, produk yang disajikan pun semakin bervariasi demi meningkatkan kepuasan konsumen. Untuk memenuhi kebutuhan konsumen dari 7.30 wita sampai dengan 21.30 wita disetiap harinya Bali Bakery cabang Hayam Wuruk telah mempekerjakan banyak pegawai untuk memenuhi kebutuhan konsumen selama 15 jam setiap harinya.

\section{Uji Validitas dan Reliabilitas}

Dilaksanakan di Conato Bakery Teuku Umar Denpasar. Hasil pengukuran validitas kusioner untuk tingkat kepentingan dan tingkat kepuasan dengan menggunakan analisis Product Moment, didapatkan bahwa nilai r pada setiap penyataan kuisioner di atas $r$ tabel $(\alpha=0,5)$ yaitu sebesar 0,3061. Berdasarkan hasil tersebut dapat disimpulkan bahwa pernyataan-pernyataan pada kuisioner tingkat kepentingan dan kepuasan adalah valid dan bisa digunakan dalam mengukur tingkat kepentingan dan tingkat kepuasan konsumen di perusahaan.

Hasil pengukuran reliabilitas kuisioner kepentingan dan kepuasan dengan menggunakan metode Alpha Cronbach didapatkan koefisien alpha $(\alpha)$ sebesar 0,873 dan 0,817 yang dimana nilai alpha $(\alpha)$ menunjukan lebih dari 0,70 (Bagozzi dan Yi, 1988, dalam Eisingerich dan Rubera, 2010: 27). Hasil tersebut dapat disimpulkan bahwa kuisioner reliabel untuk digunakan karena koefisien alpha kuisioner kepentingan dan kepuasan lebih besar daripada $r$ tabel.

\section{Tingkat Kepentingan Terhadap Masing- Masing Variabel}

Hasil skor tingkat kepentingan konsumen seperti pada Tabel 1 dapat diketahui variabel yang mempunyai total skor terendah adalah pelayanan perusahaan ketika konsumen membutuhkan sesuatu. Karyawan Bali Bakery kurang cekatan dalam membantu 
konsumen dengan nilai rata-rata 3,48 (puas) dikarenakan kurangnya kesadaran akan waktu sehingga banyaknya waktu yang terbuang saat melayani konsumen. Variabel tersebut menjadi variabel menunggu sedikit lama saat memesan sesuatu. Skor tertinggi adalah karyawan Bali Bakery mampu memberikan produk yang sangat lezat kepada konsumen yaitu dengan nilai rata-rata 4,47 (sangat penting) dikarenakan bahan-bahan yang digunakan tidak sembarangan dalam pembuatan makanan, sehingga raza tetap konstan dan selalu meningkat. Variabel ini mendapat total skor tertinggi karena konsumen beranggapan bahwa hal tersebut merupakan salah satu syarat terpenting dalam terciptanya kepuasan pelanggan.

Tabel 1. Hasil total skor tingkat kepentingan terhadap masing-masing variabel

\begin{tabular}{|c|c|c|c|c|c|c|c|c|}
\hline \multirow[b]{2}{*}{ No } & \multirow[b]{2}{*}{ Pernyataan } & \multicolumn{7}{|c|}{ Kepentingan } \\
\hline & & STP & TP & B & $\mathrm{P}$ & SP & Total & $\begin{array}{l}\text { Rata- } \\
\text { Rata }\end{array}$ \\
\hline $\mathbf{A}$ & Produk & & & & & & & \\
\hline 1 & Produk yang disajikan sangat lezat & 0 & 0 & 60 & 90 & 685 & 835 & 4,47 \\
\hline 2 & Harga produk terjangkau & 0 & 0 & 90 & 348 & 350 & 788 & 4,21 \\
\hline 3 & Beragam jenis produk sehingga tidak membosankan & 0 & 0 & 288 & 204 & 200 & 692 & 3,70 \\
\hline 4 & $\begin{array}{l}\text { Produk yang dihasilkan selalu memiliki inovasi yang } \\
\text { baru (mengikuti perkembangan jaman) }\end{array}$ & 0 & 0 & 267 & 232 & 200 & 699 & 3,74 \\
\hline 5 & $\begin{array}{l}\text { Kemasan produk (take away) mampu menjaga produk } \\
\text { agar tidak rusak hingga ke tempat tujuan }\end{array}$ & 0 & 0 & 90 & 280 & 435 & 805 & 4,30 \\
\hline 6 & Produk sangat higenis & 0 & 0 & 120 & 272 & 395 & 787 & 4,21 \\
\hline \multirow[t]{2}{*}{7} & Produk yang diinginkan selalu ada & 0 & 0 & 270 & 348 & 50 & 668 & 3,57 \\
\hline & Rata-Rata & & & & & & & 4,03 \\
\hline $\mathbf{B}$ & Jasa Pelayanan & & & & & & & \\
\hline 1 & Tersedianya lahan parkir yang memadai & 0 & 0 & 162 & 212 & 400 & 774 & 4,14 \\
\hline 2 & $\begin{array}{l}\text { Karyawan Bali Bakery cekatan dalam menangani } \\
\text { kebutuhan akan pesanan konsumen }\end{array}$ & 0 & 0 & 375 & 136 & 140 & 651 & 3,48 \\
\hline 3 & Pelayanan sesuai dengan apa yang diinginkan konsumen & 0 & 0 & 261 & 220 & 225 & 706 & 3,78 \\
\hline 4 & $\begin{array}{l}\text { Karyawan Bali Bakery memiliki pengetahuan tentang } \\
\text { produk yang dipesan }\end{array}$ & 0 & 0 & 120 & 356 & 290 & 766 & 4,10 \\
\hline 5 & $\begin{array}{l}\text { Konsumen selalu merasa aman dalam melakukan } \\
\text { transaksi }\end{array}$ & 0 & 0 & 210 & 160 & 385 & 755 & 4,04 \\
\hline 6 & $\begin{array}{l}\text { Karyawan Bali Bakery memberikan pelayanan yang sama } \\
\text { tanpa memandang status social }\end{array}$ & 0 & 0 & 174 & 196 & 400 & 770 & 4,12 \\
\hline 7 & $\begin{array}{l}\text { Bali Bakery memiliki jam buka yang sesuai dengan } \\
\text { keinginan anda }\end{array}$ & 0 & 0 & 135 & 132 & 545 & 812 & 4,34 \\
\hline 8 & Bali Bakery memiliki tempat yang bersih & 0 & 0 & 135 & 356 & 265 & 756 & 4,04 \\
\hline 9 & $\begin{array}{l}\text { Lokasi Bali Bakery mudah untuk ditemukan dekat dengan } \\
\text { tempat fasilitas umum lainnya }\end{array}$ & 0 & 0 & 117 & 192 & 500 & 809 & 4,33 \\
\hline 10 & $\begin{array}{l}\text { Konsumen tidak terlalu lama mengantri dalam membeli } \\
\text { produk }\end{array}$ & 0 & 0 & 120 & 356 & 290 & 766 & 4,10 \\
\hline 11 & $\begin{array}{l}\text { Konsumen merasa puas dengan kesopanan yang dimiliki } \\
\text { oleh karyawan Bali Bakery }\end{array}$ & 0 & 0 & 147 & 232 & 400 & 779 & 4,17 \\
\hline 12 & $\begin{array}{l}\text { Konsumen merasa puas dengan keramahan yang dimiliki } \\
\text { oleh karyawan Bali Bakery }\end{array}$ & 0 & 0 & 168 & 288 & 295 & 751 & 4,02 \\
\hline \multirow[t]{2}{*}{13} & Konsumen merasa puas dengan keamanan di Bali Bakery & 0 & 0 & 60 & 352 & 395 & 807 & 4,32 \\
\hline & Rata-Rata & & & & & & & 4,07 \\
\hline
\end{tabular}




\section{Tingkat Kinerja Terhadap Masing- Masing Variabel}

Pada penelitian ini didapatkan variabel jasa pelayanan yang mempunyai skor terendah adalah parkir di Bali Bakery (X1) dengan nilai rata-rata 3,01 (netral). Variabel ini mendapat total skor terendah karena Bali Bakery kurang memiliki area yang luas sehingga konsumen yang ingin makan langsung di lokasi kadang tidak mendapat lahan parkir dikarenakaan lahannya yang berukuran $10 \mathrm{~m} \times 12 \mathrm{~m}$ yang hanya cukup sekitar 4 sampai 5 mobil sehingga banyak konsumen yang memesan takeaway. Untuk mengatasi hal tersebut, pihak Restoran Bali
Bakery bisa mencari lahan kosong disekitar Bali Bakery untuk dijadikannya tempat parkir. Variabel yang memiliki skor tertinggi adalah karyawan Bali Bakery mampu memberikan beragam jenis produk sehingga konsumen tidak bosan untuk memesan produk yang ada di Bali Bakery dengan nilai rata-rata 4,85 (Sangat Baik). Variabel ini mendapat total skor tertinggi karena perusahaan diwajibkan untuk mampu berkreatifitas dalam hal pembuatan produk karena hal tersebut merupakan salah satu syarat terpenting dalam terciptanya kepuasan pelanggan.

Tabel 2. Hasil total skor tingkat kinerja terhadap masing-masing variabel

\begin{tabular}{|c|c|c|c|c|c|c|c|c|}
\hline \multirow[b]{2}{*}{ No } & \multirow[b]{2}{*}{ Pernyataan } & \multicolumn{7}{|c|}{ Kinerja } \\
\hline & & STB & TB & $\mathrm{N}$ & B & SB & Total & $\begin{array}{l}\text { Rata- } \\
\text { Rata }\end{array}$ \\
\hline $\mathbf{A}$ & Produk & & & & & & & \\
\hline 1 & Produk yang disajikan sangat lezat & 0 & 0 & 150 & 240 & 385 & 775 & 4,14 \\
\hline 2 & Harga produk terjangkau & 0 & 60 & 150 & 200 & 285 & 695 & 3,71 \\
\hline 3 & Beragam jenis produk sehingga tidak membosankan & 0 & 0 & 27 & 40 & 840 & 907 & 4,85 \\
\hline 4 & $\begin{array}{l}\text { Produk yang dihasilkan selalu memiliki inovasi yang } \\
\text { baru (mengikuti perkembangan jaman) }\end{array}$ & 0 & 40 & 150 & 240 & 285 & 715 & 3,82 \\
\hline 5 & $\begin{array}{l}\text { Kemasan produk (take away) mampu menjaga produk } \\
\text { agar tidak rusak hingga ke tempat tujuan }\end{array}$ & 0 & 40 & 90 & 348 & 250 & 728 & 3,89 \\
\hline 6 & Produk sangat higenis & 0 & 0 & 0 & 392 & 445 & 837 & 4,47 \\
\hline \multirow[t]{2}{*}{7} & Produk yang diinginkan selalu ada & 0 & 0 & 180 & 320 & 235 & 735 & 3,93 \\
\hline & Rata-Rata & & & & & & & 4,11 \\
\hline
\end{tabular}

\begin{tabular}{|c|c|c|c|c|c|c|c|c|}
\hline $\mathbf{B}$ & Jasa Pelayanan & & & & & & & \\
\hline 1 & Tersedianya lahan parkir yang memadai & 0 & 80 & 345 & 88 & 50 & 563 & 3,01 \\
\hline 2 & $\begin{array}{l}\text { Karyawan Bali Bakery cekatan dalam menangani } \\
\text { kebutuhan akan pesanan konsumen }\end{array}$ & 0 & 0 & 132 & 252 & 400 & 784 & 4,19 \\
\hline 3 & $\begin{array}{l}\text { Pelayanan sesuai dengan apa yang diinginkan } \\
\text { konsumen }\end{array}$ & 0 & 4 & 42 & 232 & 565 & 843 & 4,51 \\
\hline 4 & $\begin{array}{l}\text { Karyawan Bali Bakery memiliki pengetahuan tentang } \\
\text { produk yang dipesan }\end{array}$ & 0 & 20 & 150 & 188 & 400 & 758 & 4,05 \\
\hline 5 & $\begin{array}{l}\text { Konsumen selalu merasa aman dalam melakukan } \\
\text { transaksi }\end{array}$ & 0 & 0 & 180 & 240 & 335 & 755 & 4,03 \\
\hline 6 & $\begin{array}{l}\text { Karyawan Bali Bakery memberikan pelayanan yang } \\
\text { sama tanpa memandang status social }\end{array}$ & 0 & 0 & 180 & 240 & 335 & 755 & 4,03 \\
\hline 7 & $\begin{array}{l}\text { Bali Bakery memiliki jam buka yang sesuai dengan } \\
\text { keinginan anda }\end{array}$ & 0 & 10 & 150 & 220 & 385 & 765 & 4,09 \\
\hline 8 & Bali Bakery memiliki tempat yang bersih & 0 & 0 & 60 & 200 & 585 & 845 & 4,51 \\
\hline 9 & $\begin{array}{l}\text { Lokasi Bali Bakery mudah untuk ditemukan dekat } \\
\text { dengan tempat fasilitas umum lainnya }\end{array}$ & 0 & 0 & 150 & 200 & 435 & 785 & 4,19 \\
\hline 10 & $\begin{array}{l}\text { Konsumen tidak terlalu lama mengantri dalam } \\
\text { membeli produk }\end{array}$ & 0 & 10 & 132 & 240 & 390 & 772 & 4,12 \\
\hline
\end{tabular}




\begin{tabular}{l|llllllll}
$\mathbf{1 1}$ & $\begin{array}{l}\text { Konsumen merasa puas dengan kesopanan yang } \\
\text { dimiliki oleh karyawan Bali Bakery }\end{array}$ & 0 & 4 & 165 & 136 & 480 & 785 & 4,19 \\
$\mathbf{1 2}$ & $\begin{array}{l}\text { Konsumen merasa puas dengan keramahan yang } \\
\text { dimiliki oleh karyawan Bali Bakery }\end{array}$ & 0 & 0 & 180 & 240 & 335 & 755 & 4,03 \\
$\mathbf{1 3}$ & $\begin{array}{l}\text { Konsumen merasa puas dengan keamanan di Bali } \\
\text { Bakery }\end{array}$ & 0 & 2 & 138 & 264 & 370 & 774 & 4,13 \\
\hline & Rata-Rata & & & & & 4,08 \\
\hline
\end{tabular}

\section{Pengukuran Indeks Kepuasan Konsumen}

Perhitungan indeks kepuasan konsumen terhadap kualitas produk dapat dilihat pada Tabel 3. Nilai total skor adalah total hasil perkalian antara rata-rata tingkat kepentingan dengan rata-rata tingkat kepuasan

Tabel 3. Perhitungan indeks kepuasan konsumen Bali Bakery

\begin{tabular}{llccc}
\hline \multirow{2}{*}{ No } & \multicolumn{1}{c}{ Pernyataan } & $\begin{array}{c}\text { Kepuasan } \\
(\mathrm{X})\end{array}$ & $\begin{array}{c}\text { Kepentingan } \\
(\mathrm{Y})\end{array}$ & $\begin{array}{c}\text { Total } \\
(\mathrm{X} . \mathrm{Y})\end{array}$ \\
\hline \multicolumn{1}{c}{ Kualitas Produk } & & & \\
\hline 1 & Produk yang disajikan sangat lezat & 4,14 & 4,46 & 18,46 \\
2 & Harga produk terjangkau & 3,71 & 4,21 & 15,62 \\
3 & Beragam jenis produk sehingga tidak membosankan & 5,06 & 3,7 & 18,72 \\
4 & Produk yang dihasilkan selalu memiliki inovasi yang baru (mengikuti & 3,82 & 3,73 & 14,25 \\
& perkembangan jaman) & & \\
5 & Kemasan produk (take away) mampu menjaga produk agar tidak rusak & 3,89 & 4,3 & 16,73 \\
& hingga ke tempat tujuan & 4,47 & 4,2 & 18,77 \\
6 & Produk sangat higenis & 3,93 & 3,57 & 14,03 \\
\hline & Produk yang diinginkan selalu ada & 29,02 & 28,17 & 116,59 \\
\hline & Skor Total $(\Sigma)$ & 4,14 & 4,02 & 16,65 \\
\hline & Rata-Rata & & & \\
\hline
\end{tabular}

Sedangkan untuk perhitungan indeks kepuasan konsumen terhadap kualitas

pelayanan dapat dilihat pada Tabel 4 .

Tabel 4. Perhitungan indeks kepuasan konsumen terhadap kualitas pelayanan

\begin{tabular}{clccc}
\hline No & \multicolumn{1}{c}{ Pernyataan } & $\begin{array}{c}\text { Kepuasan } \\
(\mathrm{X})\end{array}$ & $\begin{array}{c}\text { Kepentingan } \\
(\mathrm{Y})\end{array}$ & $\begin{array}{c}\text { Total } \\
(\mathrm{X} . \mathrm{Y})\end{array}$ \\
\hline & \multicolumn{1}{c}{ Kualitas Produk } & & & \\
\hline 1 & Tersedianya lahan parkir yang memadai & 3,01 & 4,13 & 12,43 \\
2 & Karyawan Bali Bakery cekatan dalam menangani kebutuhan akan & 4,19 & 3,48 & 14,58 \\
& pesanan konsumen & & & \\
3 & Pelayanan sesuai dengan apa yang diinginkan konsumen & 4,51 & 3,77 & 16,96 \\
4 & Karyawan Bali Bakery memiliki pengetahuan tentang produk yang & 4,05 & 4,09 & 16,56 \\
& dipesan & & & \\
5 & Konsumen selalu merasa aman dalam melakukan transaksi & 4,03 & 4,03 & 16,24 \\
6 & Karyawan Bali Bakery memberikan pelayanan yang sama tanpa & 4,03 & 4,11 & 16,56 \\
& memandang status social & & & \\
7 & Bali Bakery memiliki jam buka yang sesuai dengan keinginan anda & 4,09 & 4,34 & 17,75 \\
8 & Bali Bakery memiliki tempat yang bersih & 4,51 & 4,04 & 18,22 \\
9 & Lokasi Bali Bakery mudah untuk ditemukan dekat dengan tempat & 4,19 & 4,32 & 18,10 \\
& fasilitas umum lainnya & & & \\
10 & Konsumen tidak terlalu lama mengantri dalam membeli produk & 4,12 & 4,09 & 16,85 \\
11 & Konsumen merasa puas dengan kesopanan yang dimiliki oleh & 4,19 & 4,16 & 17,43
\end{tabular}




\begin{tabular}{llccc}
12 & $\begin{array}{l}\text { Konsumen merasa puas dengan keramahan yang dimiliki oleh } \\
\text { karyawan Bali Bakery }\end{array}$ & 4,03 & 4,01 & 16,16 \\
13 & 4,13 & 4,31 & 17,80 \\
\hline Konsumen merasa puas dengan keamanan di Bali Bakery & 53,07 & 52,88 & 215,65 \\
\hline Skor Total $(\Sigma)$ & 4,08 & 4,01 & 16,58 \\
\hline Rata-Rata & &
\end{tabular}

Berdasarkan hasil perhitungan indeks kepuasan konsumen sebesar 80,34\% terhadap kualitas produk dan sebesar $81,27 \%$ terhadap kualitas pelayanan, maka sesuai dengan kriteria indeks kepuasan karyawan sebesar $80 \%$ atau lebih dari $80 \%$, hal ini mengindikasikan bahwa konsumen merasa puas terhadap kualitas produk dan kualitas pelayanan yang diberikan oleh Bali Bakery

\section{Pengukuran Importance Performance Analysis}

Diagram kartesius tingkat kepuasan dan kepentingan konsumen terhadap kualitas produk Bali Bakery dapat dilihat pada gambar berikut:

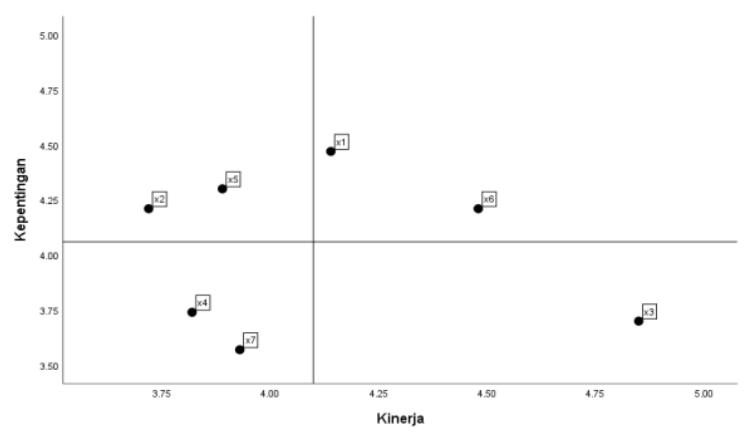

Gambar 3. Diagram kartesius tingkat kinerja dan kepentingan konsumen terhadap kualitas produk Bali Bakery

\section{Kuadran A (Tingkatkan Kinerja)}

Atribut-atribut yang berada di kuadran A merupakan atribut yang dianggap penting oleh responden, namun kinerja yang diterima dalam pelaksanaannya dinilai kurang oleh konsumen. Atribut tersebut adalah harga produk terjangkau (X2) dan kemasan produk (take away) mampu menjaga produk agar tidak rusak hingga ke tempat tujuan (X5). Dalam hal ini berarti Bali Bakery harus meningkatkan kinerja atribut yang berada di kuadran ini karena belum maksimal agar mencapai harapan dari konsumen sehingga tercapai kepuasan konsumen yang diinginkan.

\section{Kuadran B (Pertahankan Kinerja)}

Atribut-atribut yang berada di kuadran B merupakan atribut yang dianggap penting oleh responden dan kinerja yang diterima dalam pelaksanaannya dinilai sudah sesuai dengan harapan konsumen. Atribut-atribut tersebut meliputi produk yang disajikan sangat lezat (X1), produk sangat higenis (X6). Hal ini berarti Bali Bakery sudah melaksanakan atribut-atribut tersebut dengan baik sehingga tercapai kepuasan konsumen.

\section{Kuadran C (Prioritas Rendah)}

Atribut-atribut yang berada di kuadran C merupakan atribut yang dianggap kurang penting oleh responden dan kinerja yang diterima dalam pelaksanaannya juga dinilai kurang. Atribut-atribut tersebut meliputi produk yang dihasilkan selalu memiliki inovasi yang baru (mengikuti perkembangan jaman) (X4), produk yang diinginkan selalu ada (X7). Hal ini berarti Bali Bakery perlu meningkatkan kinerja dari atribut-atribut ini agar tercapai kepuasan maksimal dari konsumen.

\section{Kuadran D (Cenderung Berlebihan)}

Atribut-atribut yang berada di kuadran D merupakan atribut yang dianggap kurang penting oleh responden namun kinerja yang diterima dalam pelaksanaannya sudah sangat baik. Atribut tersebut adalah Bali Bakery memiliki beragam jenis produk sehingga tidak membosankan (X3). Hal ini berarti Bali Bakery cukup mempertahankan kinerja dari 
atribut ini namun jangan terlalu berlebihan dalam pelaksanaannya.

Sedangkan diagram kartesius untuk tingkat kepuasan dan kepentingan konsumen terhadap kualitas pelayanan Bali Bakery dapat dilihat pada gambar berikut.

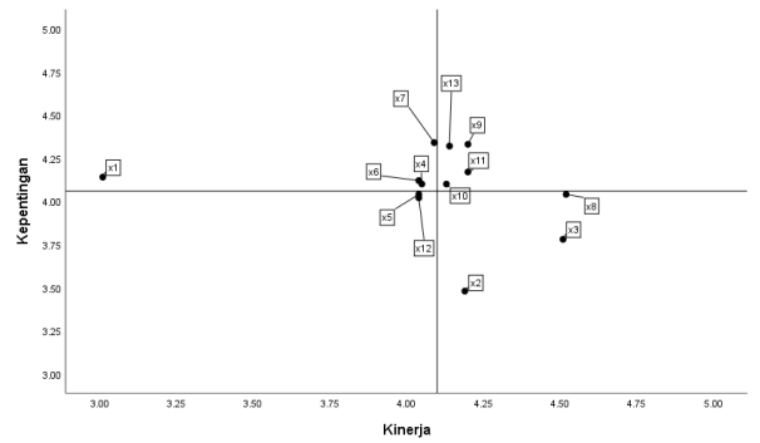

Gambar

2. Diagram kartesius tingkat kepuasan dan kepentingan konsumen terhadap kualitas pelayanan Bali Bakery.

\section{Kuadran A (Tingkatkan Kinerja)}

Atribut-atribut yang berada di kuadran A merupakan atribut yang dianggap penting oleh responden. Namun kinerja yang diterima dalam pelaksanaannya dinilai kurang oleh konsumen. Atribut-atribut tersebut meliputi tersedianya lapangan parkir yang memadai (X1), karyawan Bali Bakery memiliki pengetahuan tentang produk yang dipesan (X4), karyawan Bali Bakery memberikan pelayanan yang sama tanpa memandang status social (X6), Bali Bakery memiliki jam buka yang sesuai dengan keinginan anda (X7). Dalam hal ini berarti Bali Bakery harus meningkatkan kinerja atribut yang berada di kuadran ini bisa dengan meningkatkan dengan cara menambah lahan parkir, meningkatkan kenyamanan dalam hal melayani konsumen siapapun tanpa melihat status sosial dan menambah jam buka agar pelanggan bisa datang sehingga tercapai kepuasan konsumen yang diinginkan.

\section{Kuadran B (Pertahankan Kinerja)}

Atribut-atribut yang berada di kuadran
B merupakan atribut yang dianggap penting oleh responden dan kinerja yang diterima dalam pelaksanaannya dinilai sudah sesuai dengan harapan konsumen. Atribut-atribut tersebut meliputi lokasi Bali Bakery mudah untuk ditemukan dekat dengan tempat fasilitas umum lainnya (X9), Konsumen tidak terlalu lama mengantri dalam membeli produk (X10), merasa puas dengan kesopanan yang dimiliki oleh karyawan Bali Bakery (X11), merasa puas dengan keamanan di Bali Bakery (X13). Hal ini berarti Bali Bakery sudah melaksanakan atribut-atribut tersebut dengan baik sehingga tercapai kepuasan konsumen.

\section{Kuadran C (Prioritas Rendah)}

Atribut-atribut yang berada di kuadran $\mathrm{C}$ merupakan atribut yang dianggap kurang penting oleh responden dan kinerja yang diterima dalam pelaksanaannya juga dinilai kurang. Atribut-atribut tersebut meliputi konsumen selalu merasa aman dalam melakukan transaksi (X5), konsumen merasa puas dengan keramahan yang dimiliki oleh karyawan Bali Bakery (X12). Hal ini berarti Bali Bakery kurang cukup baik dalam melaksanakan kinerja pada atribut tersebut sehingga tetapi harus tetap ditingkatkan agar tercapai kepuasan maksimal dari konsumen.

\section{Kuadran D (Cenderung Berlebihan)}

Atribut-atribut yang berada di kuadran D merupakan atribut yang dianggap kurang penting oleh responden namun kinerja yang diterima dalam pelaksanaannya sudah sangat baik. Atribut tersebut adalah karyawan Bali Bakery cekatan dalam menangani kebutuhan akan pesanan konsumen (X2), pelayanan sesuai dengan apa yang diinginkan konsumen (X3) dan Bali Bakery memiliki tempat yang bersih (X8). Hal ini berarti Bali Bakery perlu mempertahankan kinerja dari atribut ini namun jangan terlalu berlebihan dalam pelaksanaannya. 


\section{KESIMPULAN DAN SARAN}

\section{Kesimpulan}

Berdasarkan penelitian yang telah dilakukan maka dapat disimpulkan beberapa hal sebagai berikut :

1. Tingkat kepentingan terhadap kualitas produk, variabel yang mendapatkan skor tertinggi adalah produk yang disajikan sangat lezat dengan nilai rata-rata 4,47 (sangat penting), sedangkan variabel dengan nilai terendah adalah produk yang diinginkan selalu ada dengan nilai rata-rata 3,57 (penting), dan yang memiliki skor paling rendah di keseluruhan pelayanan dan produk yaitu karyawan Bali Bakery cekatan dalam menangani kebutuhan akan pesanan konsumen dengan total skor 3,48 (penting). Pada tingkat kinerja terhadap kualitas produk, variabel dengan skor tertinggi adalah beragam jenis produk sehingga tidak membosankan nilai ratarata 4,85 (sangat baik) dan menjadi skor tertinggi dalam semua variabel kinerja. Variabel yang memiliki skor terendah adalah rasa harga produk terjangkau dengan nilai rata-rata 3,71 (baik), namun skor terendah terdapat pada variabel tersedianya lahan parkir yang memadai yang memiliki skor 3,00 (netral).

2. Indeks kepuasan konsumen sebesar $80,40 \%$ terhadap kualitas produk dan sebesar $81,27 \%$ terhadap kualitas pelayanan, maka sesuai dengan kriteria indeks kepuasan karyawan sebesar $80 \%$ atau lebih dari $80 \%$, hal ini mengindikasikan bahwa konsumen merasa puas terhadap kualitas produk dan kualitas pelayanan yang diberikan oleh Bali Bakery

3. Variabel yang perlu mendapatkan prioritas untuk dilakukan perbaikan dari Bali Bakery berdasarkan tingkat kepentingan dan tingkat kepuasan konsumen adalah seluruh variabel yang berada di kuadran A, yaitu harga produk terjangkau, kemasan produk (take away) mampu menjaga produk agar tidak rusak hingga ke tempat tujuan, karyawan Bali Bakery memiliki pengetahuan tentang produk yang dipesan, tersedianya lapangan parkir yang memadai, karyawan Bali Bakery memberikan pelayanan yang sama tanpa memandang status social, dan Bali Bakery memiliki jam buka yang sesuai dengan keinginan anda.

\section{Saran}

Dalam hal ini berarti Bali Bakery harus bisa memikat konsumen dengan cara memberikan bonus atau diskon dalam pembelian setiap produk, bisa merubah kemasan lebih aman lagi seperti memberikan tempat yang lebih tebal agar saat sampai ditempat lebih aman, setiap minggunya diadakan tes untuk karyawan agar lebih memahami produk bali bakery dan bisa menjelaskan lebih baik untuk setiap produknya kepada konsumen, mencari lahan tambahan di sekitar tempat tersebut, menambahkan tingkat kenyamanan dalam hal melayani siapapun, menambah waktu buka agar semua kensumen masih bisa berbelanja ditempat tersebut.

\section{DAFTAR PUSTAKA}

Dwiwinarsih, 2009. Analisis Tingkat Kepuasan Konsumen Terhadap Pelayanan Bakmi Aisy di Depok. Dalam Jurnal Manajemen.

Hall, S. 2010, "How to Use the Likert Scale in Statistical Analysis", Online.

Iswari, I. A. M., A. A. P. A. S. Wiranatha., I. K. Satriawan. 2015. Analisis Kepuasan Konsumen Terhadap Kualitas Pelayanan dan Jasa dengan Menggunakan Metode Importance Performance Analysis (Studi Kasus di 
Restoran Warung Subak Peguyangan Denpasar). Jurnal Rekayasa dan Manajemen Agroindustri. 3 (3): 51-60.

John, AM and J.C. James. 1977. "Importance-Performance Analysis" (Journal of Marketing, January, 1977) pp. $77-79$.

Kotler, J. 1989. Manajemen Pemasaran: Analisis, Perencanaan dan Pengendalian. Jakarta: Erlangga.

Lerbin, R. 2005. Kepuasan Konsumen, Pengukuran dan Penganalisisan dengan SPSS. PT. Gramedia Pustaka, Jakarta.

Jentrasaswin, G. P., A. A. P. A. S. Wiranatha., I. K. Satriawan. 2018. Analisis Tingkat Kepuasan Konsumen Terhadap Kualitas Produk dan Kualitas Pelayanan di Restoran Cepat Saji Mcdonal's Cabang Robinson, Denpasar. Jurnal Rekayasa dan Manajemen Agroindustri. 6 (2) : 125134.

Ranitaswari, P. A., S. Mulyani., C. A. B. Sadyasmara. 2018. Analisis Kepuasan Konsumen Terhadap Kualitas Produk Kopi dan Kualitas Pelayanan Menggunakan Metode Importance Performance Analysis (Studi Kasus Di Geo Coffe). Jurnal Rekayasa dan Manajemen Agroindustri. 6 (2) : 147157.
Saifuddin, A. 1997. Reliabilitas dan Validitas. Pustaka Pelajar Offset, Yogyakarta.

Sevilla, dkk., 1993. Pengantar Metode Penelitian. UI Press, Jakarta.

Singarimbun, Masri dan S. Effendi. 1989. Metode Penelitian Survey. LP3ES, Jakarta.

Siregar, E.H. dan Yesenia. 2014. Pengaruh Kualitas Layanan dan Produk terhadap Kepuasan serta Loyalitas Pelanggan Kentucky Fried Chicken di Tangerang Selatan. Jurnal Manajemen dan Organisasi.

Sumanto. 2006. Statistika Deskriptif. Penerbit CAPS, Yogyakarta.

Supranto, J. 2003. Metode Riset. PT Asdi Mahastya, Jakarta.

Supranto, J. 2001. Statistik Teori dan Aplikasi, Edisi 6, Erlangga, Jakarta. 